\title{
Experimental study on fatigue properties of Q420C steel welded joints at room temperature
}

\author{
Liguo Yang ${ }^{a, b}$ (D), Yongming Xing ${ }^{b *}$ (iD) \\ a Key Laboratory of Civil Engineering Structure and Mechanics, Inner Mongolia University of Technology, Hohhot, 010051,China. \\ Email:76351789@qq.com \\ ${ }^{\mathrm{b}}$ School of Science, Inner Mongolia University of Technology, Hohhot, 010051, China. Email:xym@imut.edu.cn \\ * Corresponding author
}

https://doi.org/10.1590/1679-78256808

\begin{abstract}
To evaluate the fatigue life of Q420C steel welded joints, fatigue tests were performed on butt-welded joints, cross-butt-welded joints and cross-fillet-welded joints. The fatigue strength $\mathrm{S}-\mathrm{N}$ curves of the joints were fitted. Then the formation and development of fatigue cracks were analyzed by fracture morphology. The fatigue properties of joints were compared with literature data and standard curves. The results showed that the fatigue test data of the three types of welded joints were roughly above the standard curves. Moreover, the fatigue strength of butt-welded joint was significantly higher than the calculated values of standards, indicating a large safety margin. The test value of cross-butt-welded joint was close to the calculated values of standards, so it is suggested to moderately reduce the standard values. In addition, all the three standards could well predict the fatigue life of cross-fillet-welded joint. The fracture morphology of the specimens showed the development process of fatigue damage, and the fatigue displacement curve and damage curve proved the formation of the fatigue fracture in specimens.
\end{abstract}

\section{Keywords}

Butt-welded joint; Cross-butt-welded joint; Cross-fillet-welded joint; Fatigue damage; S-N curve

\section{Graphical abstract}
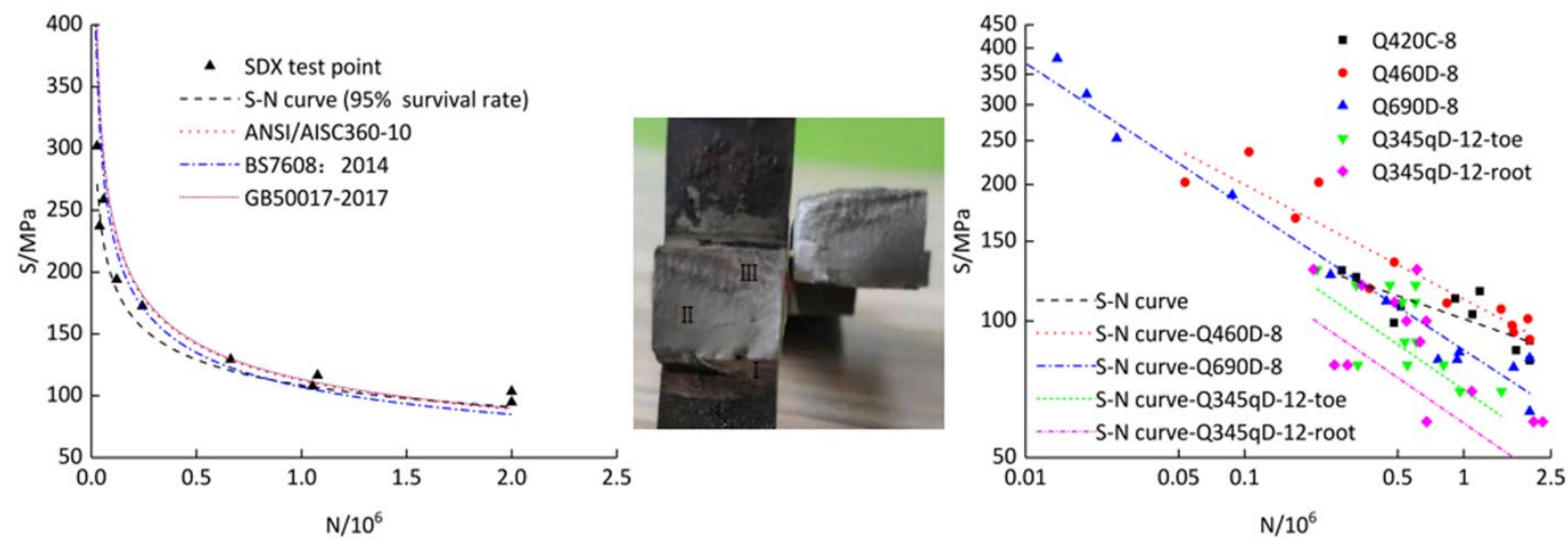


\section{INTRODUCTION}

With the wide application of Q420 steel in transmission towers, offshore drilling platforms and large public structures, the strength, toughness, fatigue resistance, machinability, welding performance and corrosion resistance of Q420 steel welded joints have become the focuses of structural engineers. About $80 \%$ of the failure of metal structures is resulted from the fatigue fracture of materials or connections(Lei et al., 2010). The structural deformation is quite small before fatigue fracture occurs, and no obvious macroscopic plastic deformation can be observed. But sudden fatigue damage often induces huge loss to life and property.

Many studies were carried out on the fatigue performance of various steels and welded connections. Lei et al. (2010) summarized the research progress in the fatigue of steel structures in China in the past 30 years from six aspects (fatigue load spectrum, fatigue influencing factors, fatigue failure mechanism, fatigue test methods, fatigue life estimation, and fatigue design methods), and pointed out the fatigue problems to be solved for steel structure. Jia et al. (2017) carried out static tensile test and axial tensile fatigue test respectively on standard round rod specimens and hourglass-shaped smooth specimens. They found that Q345qD butted weld had better fatigue, and the fatigue life was significantly improved with the decreasing stress, and gave the fitting formula of fatigue life with varying stress. Zong et al. (2017a, 2017b) performed fatigue tests on 26 non-bearing Q345qD steel cross-fillet welds, and plotted the S$\mathrm{N}$ curve of weld leg failure and root failure. Moreover, they developed a three-dimensional mixed-mode fatigue crack propagation analysis method to compare the predicted fatigue life with the experimental one, providing a reference for the fatigue evaluation of fillet welds. Cheng et al. (2017) conducted normal temperature fatigue performance tests on L125×12 angle steel plates with strength grades of Q420B and Q420C, and obtained the S-N curves of the two kinds of steels. The results showed that Q420C steel had an advantage over Q420B steel in fatigue performance under the same conditions, and the test results were much higher than the value prescribed in the GB 50017-2003 standard.

Defects are inevitable in the welding process. Adjusting the welding process or adopting post-weld treatment can improve the fatigue performance of the weld. Janosch et al. (1996) studied the fatigue properties of four steels (Domex350, Domex590, Weldox700 and Weldox900) with steel strength variation after weld treatment. Custafsson (2002) tested the effect of thickness change on the fatigue performance of the $3 \sim 12 \mathrm{~mm}$ thick Domex550 MC, a high-strength steel, through cross-welded joints. The study showed that the fatigue performance decreased with the increasing plate thickness. Weich I (2008) studied the impact of post-weld treatment on the fatigue properties of S355J2 and S690QL steels. Leitner $M$ et al. (2011) analyzed the influence of welding process and high-frequency shot peening technology on the fatigue properties of S960 steel. Okawa T et al. (2013) investigated the impact of different stress ratios and post-welding technologies on fatigue strength of AH36 steel cross welded joints. The test results showed that the greater the stress ratio, the smaller the fatigue strength, and that the fatigue limit of the welded joint after ultrasonic treatment was significantly improved. Through S-N curve and microstructure analysis, Zhang et al. (2020) studied the fatigue properties of Q420 steel butt welds treated with three different welding processes (SMAW, SMAW+FCAW and SMAW+SAW). They found that the 1102 welded joint produced by SMAW primer + SAW filling cover was far better than the other two joints in fatigue performance.

The existing studies on the fatigue properties of welded steel mainly focus on low or high strength structural steel. Few are on the welding fatigue properties of medium strength Q420 steel with broad applicability. Moreover, the welded joints are mostly butt welding and non-load-bearing cross-fillet welding; cross-butt welding has not been studied. In addition, the fatigue test data of welded joints in current steel structure design need to be improved, so it is necessary to carry out fatigue test on Q420C steel welded joints.

In this work, the fatigue properties of three kinds of Q420C structural steel welded joints at room temperature were studied by experiments. The S-N curve of fatigue strength of the joints was fitted with the test data. In addition, the development of fatigue cracks is analyzed based on the fracture morphology, and the fatigue life of welded joints is compared with literature data and specification curves, which provides reference for the fatigue performance of Q420C structural steel welded joints.

\section{Test Overview}

\subsection{Test materials}

The Q420C steel used in this test was an $8 \mathrm{~mm}$ thick steel plate. It meets the requirements of Chinese standard GB/T1591-2008 (2009). The chemical composition and melting analysis results of the steel plate are listed in Table 1. Manual arc welding was the welding method. Electric electrode was the Dongfeng SH.J557 fine grain steel manual electrode produced by Shanghai Welding Equipment Co., Ltd. The yield strength and tensile strength of the cladding metal were not less than $460 \mathrm{MPa}$ and $550 \mathrm{MPa}$ respectively, and its elongation was at least $17 \%$. 
Tab. 1 Melting analysis of Q420C steel plate (\%)

\begin{tabular}{ccccccccc}
\hline $\begin{array}{c}\text { Chemical } \\
\text { compositions }\end{array}$ & C & Si & Mn & Cr & Mo & B & V & C \\
\hline Measured value & 0.14 & 0.042 & 0.8 & 0.015 & 0 & - & 0 & 0.278 \\
Factory value & 0.07 & 0.19 & 1.08 & 0.02 & 0.004 & - & 0 & - \\
Product standard & 0.20 & 0.50 & 1.7 & 0.30 & 0.20 & - & 0.20 & 0.45 \\
\hline
\end{tabular}

\subsection{Specimen design}

By referring to the relevant regulations in Test Methods for Cruciform Joins of Building Steel Structures (JG/T 288-2013,2013) and Metallic Materials-Fatigue Testing-Axial-Force-Controlled Method (GB/T3075-2008,2018), specimens with three kinds of welded joints were designed and fabricated, as shown in Fig. 1. The parameters adopted for the welding process are listed in Table 2. The connection types are shown in Figure 1: (a) butt-welded joint, (b) cross-butt-welded joint, and (c) cross-fillet-welded joint. The weld quality was tested by ultrasonic and radiographic testing, and it met the requirements of Code for Welding of Steel Structures (GB50611-2011, 2012). The butt-welded joint specimen was processed by wire cutting and the residual part of the weld was removed. The cross section is calculated by $A=15 \mathrm{~mm} \times 8 \mathrm{~mm}=120 \mathrm{~mm}^{2}$. The cross-butt-welded joint specimen was processed by wire cutting and the weld remained intact. The actual sizes of the four legs of the cross-fillet-welded joint were measured, which were averaged to be $h f \approx 5.7 \mathrm{~mm}$. Corresponding effective cross-sectional area in strength calculation is $A_{e}=0.7 h_{f} l_{w}=0.7 \times 5.7 \times 15 \mathrm{~mm}^{2}=120 \mathrm{~mm}$.
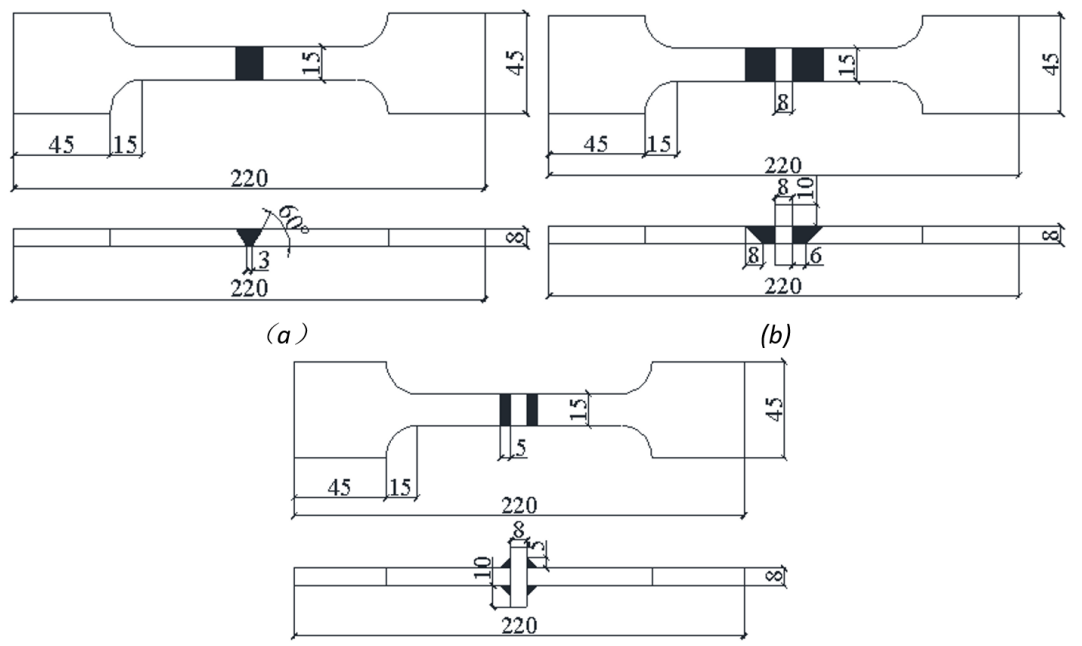

(c)

Fig. 1 Sample preparation(mm): (a) Butt-welded joint,(b) Cross-butt-welded joint,(c) Cross-fillet-welded joint.

Tab. 2 Welding parameters

\begin{tabular}{ccccc}
\hline Welding method & Diameter of electrode $/ \mathbf{m m}$ & $\begin{array}{c}\text { Welding } \\
\text { current/A }\end{array}$ & Welding voltage/V & Welding speed/cm.min $^{-1}$ \\
\hline Manual arc welding & 3.2 & 110 & 40 & $20^{\sim 25}$ \\
\hline
\end{tabular}

\subsection{Test procedure}

All specimens were subjected to monotonic tensile mechanical property test and tensile fatigue test on MTS fatigue testing machine. For each type of welding connection, 3 monotonic loading specimens and 12 cyclic loading specimens were designed, with a total of 45 specimens, as shown in Table 3 . The monotone tensile test was controlled by displacement loading at a loading rate of $0.4 \mathrm{~mm} / \mathrm{min}$ until the specimen was destroyed. The fatigue loading at room temperature was controlled by force at a frequency of $10 \mathrm{~Hz}$. The load waveform was alternating load of sinusoidal amplitude. The stress ratio was $R=P_{\min } / P_{\max }=0.1$. The value of $P_{\max }$ was calculated by $k F_{y}$, where $k$ was the loading coefficient, and Fy was the yield load of the specimen. Considering that the load would not exceed $0.66 F_{y}$ under normal use (ANSI/AISC360-10, 2010), the initial value of $k$ was 0.7 times the yield load $F_{y}$ of monotonic tension. By adjusting the value of $\mathrm{K}$ for other specimens, the experiment ends until the number of cycles $\mathrm{N}$ reaches 2 million. 
Tab. 3 Sample grouping

\begin{tabular}{cccc}
\hline Connection type & Test type & Group type & Number \\
\hline \multirow{2}{*}{ Butt-welded joint } & Mechanical test & MDD & 3 \\
& Fatigue test & MDX & 12 \\
Cross-butt-welded joint & Mechanical test & SDD & 3 \\
& Fatigue test & SDX & 12 \\
Cross-fillet-welded joint & Mechanical test & SJD & 3 \\
& Fatigue test & SJX & 12 \\
\hline
\end{tabular}

\section{Study on Fatigue Theory}

From the point of view of fracture mechanics, fatigue failure is a process of gradual crack propagation. A large number of fatigue failure cases have been supported by the theory of linear elastic fracture mechanics. According to Paris, there is a log-linear relationship between the fatigue crack growth rate $\frac{\mathrm{da}}{\mathrm{dN}}$ and the stress intensity factor $\Delta K$, known as the Paris law (Chen, 2005):

$\frac{\mathrm{da}}{\mathrm{dN}}=\mathrm{C}(\Delta \mathrm{K})^{\mathrm{n}}$

By integrating Eq. (1), the fatigue life expression when $\mathrm{C}$ and $\mathrm{n}$ are material-related constants can be obtained:

$\mathrm{N}=\frac{1}{\mathrm{C}} \int_{\mathrm{a}_{1}}^{\mathrm{a}_{2}} \frac{\mathrm{da}}{(\Delta \mathrm{K})^{\mathrm{n}}}$

where $\mathrm{a}_{1}$ and $\mathrm{a}_{2}$ are the initial crack size and the crack size at the end of the slow growth stage, respectively. The change of stress intensity factor $\Delta \mathrm{K}=\alpha \sqrt{\pi \mathrm{a}} \times \Delta \sigma$, where $\Delta \sigma$ is the stress variation range. $\Delta \sigma=\mathrm{S}_{\max }-\mathrm{S}_{\min }=\mathrm{S}$, which is substituted into Eq. (2) to get:

$\mathrm{N}=(\Delta \sigma)^{-\mathrm{n}}\left[\frac{1}{\mathrm{c}} \int_{\mathrm{a}_{1}}^{\mathrm{a}_{2}} \frac{\mathrm{da}}{(\alpha \sqrt{\pi \mathrm{a}})^{\mathrm{n}}}\right]$

$\mathrm{N}=\beta(\Delta \sigma)^{-\mathrm{n}}$

$\log N=\log \beta-\operatorname{nlog}(\Delta \sigma)$

In the above equations, $\beta=2\left(C \pi^{3 / 2} \sqrt{\mathrm{a}_{1}}\right)^{-1}$. The fatigue properties of materials are usually described by S-N relation.

$\log S=A+B \log N$

$\mathrm{S}^{\mathrm{m}} \mathrm{N}=\mathrm{C}$

where $S$ is the nominal stress range of the section; $N$ is the number of cycles of fatigue damage; $m, A, B$, and $C$ are undetermined constants.

BS7608: 2014 is a standard for design and evaluation of fatigue resistance of steel structures based on nominal stress method and hot spot stress method established through fatigue test data of a series of welded joints. This standard is applicable to base materials with steel yield strength of $200 \sim 960 \mathrm{MPa}$ and various welded joints. Fatigue assessment of various welded structures can be achieved through S-N curve. The fatigue types of components and connections stipulated in the BS7608 standard has 13 categories and grades. And the welded joints are divided into 12 design categories: B, C, D, E, F, F2, G, G2, WI, S1, S2, and TJ according to details such as weld form, joint size, fatigue load direction, and crack initiation position (BS7608-2014, 2015). For each design category, the stress range Sr and the number of fatigue cycles $\mathrm{N}$ satisfy the following equation.

$\log \mathrm{N}=\log \mathrm{C}_{0}-\mathrm{dSD}-\mathrm{mlog}_{\mathrm{r}}$ 
where $\mathrm{N}$ is the number of fatigue test results, $\mathrm{S}_{\mathrm{r}}$ is the stress range in any one cycle, $\mathrm{C}_{0}$ is the parameter defining the mean line $\mathrm{S}_{\mathrm{r}}-\mathrm{N}$ relationship, $\mathrm{m}$ is the inverse slope of $\log \mathrm{S}_{\mathrm{r}}-\log \mathrm{N}$ curve, $\mathrm{SD}$ is the standard deviation of logN, $d$ is the number of standard deviation of logN from the mean $\mathrm{S}_{r}-\mathrm{N}$ curve. Table 4 gives the values of BS7608 parameters corresponding to the three types of welded joints.

Tab. 4 Fatigue parameter value of BS7608

\begin{tabular}{ccccc}
\hline Connection type & Classes & Parameter C0 & SD & m \\
\hline Butt-welded joint & E & $3.289 \times 1012$ & 0.2509 & 3 \\
Cross-butt-welded joint & F2 & $1.231 \times 1012$ & 0.2279 & 3 \\
Cross-fillet-welded joint & W1 & $2.5 \times 1011$ & 0.2140 & 3 \\
\hline
\end{tabular}

In the Standard for Design of Steel Structures (GB50017-2017, 2017), the allowable stress design method based on the nominal stress is adopted for fatigue design calculation. The component and the connection are in an elastic state; the allowable stress amplitude depends on the types of component and the connection, the number of stress cycles, and the thickness of the plate. The fatigue checking calculation of the connections is carried out by formula (6), and the values of the parameters in the formula are shown in Table 5.

$\Delta \sigma \leq[\Delta \sigma]$

$[\Delta \sigma]=(C / N)^{1 / \beta}$

Tab. 5 Fatigue paramete value of GB50017

\begin{tabular}{cccc}
\hline Connection type & Classes & Parameter C & Parameter $\boldsymbol{\beta}$ \\
\hline Butt-welded joint & Z2 & $861 \times 1012$ & 4 \\
Cross-butt-welded joint & Z6 & $1.46 \times 1012$ & 3 \\
Cross-fillet-welded joint & Z8 & $0.72 \times 1012$ & 3 \\
\hline
\end{tabular}

The ANSI/AISC360-10 standard subdivides the fatigue calculation stress categories of base materials, welded joints, bolts and screws into A, B, B', C, C', C', D, E, F, and G (ANSI/AISC360-10, 2010). The allowable stress amplitudes of the three kinds of connections in this paper are given by the corresponding formulae below.

$\mathrm{F}_{S R}=\left\{\begin{array}{c}\left(\frac{C_{f} \times 329}{N}\right)^{0.333} B(\text { Butt }- \text { welded joint }) \\ \left(\frac{14.4 \times 10^{11}}{N}\right)^{0.333} C(\text { Cross - butt - welded joint }) \\ R_{F I L}\left(\frac{14.4 \times 10^{11}}{N}\right)^{0.333} C^{\prime \prime}(\text { Cross }- \text { fillet - welded joint })\end{array}\right.$

$R_{F I L}=\left(\frac{0.10+1.24\left(\omega / t_{p}\right)}{t_{p}^{0.167}}\right) \leq 1.0$

where $\mathrm{F}_{S R}$ is the allowable stress amplitude, $\mathrm{N}$ is the number of stress cycles, $\mathrm{C}_{\mathrm{f}}$ is the fatigue category constant whose value is $120 \times 10^{8}, R_{F I L}$ is the reduction factor of the joint's transverse fillet weld on both sides, $\omega$ is the size of leg, whose value is $5 \mathrm{~mm}$, and $t_{p}$ is the thickness of the tensile plate and its value is $8 \mathrm{~mm}$.

In the test on the three connection types, the stress range $\Delta \sigma$ is calculated according to the stress ratio 0.1 , i.e. $\mathrm{R}=\mathrm{P}_{\max } / \mathrm{P}_{\min }=\mathrm{S}_{\max } / \mathrm{S}_{\min }=0.1$. Thus, $\Delta \sigma=0.9 \mathrm{~S}_{\max }=\mathrm{S}$. Then the $\mathrm{S}-\mathrm{N}$ relationship in Table 6 is obtained by substituting the parameters of various standards into the corresponding formulae. 
Tab. 6 S-N relationship

\begin{tabular}{cccc}
\hline Connection type & BS7608: 2014 & GB50017-2017 & ANSI/AISC360-10 \\
\hline Butt-welded joint & $\mathrm{S}=14857.29 \mathrm{~N}^{(-1 / 3)}$ & $\mathrm{S}=5419.92 \mathrm{~N}^{-0.25}$ & $\mathrm{~S}=15652.89 \mathrm{~N}^{-0.333}$ \\
Cross-butt-welded joint & $\mathrm{S}=10707.39 \mathrm{~N}^{(-1 / 3)}$ & $\mathrm{S}=11333.88 \mathrm{~N}^{(-1 / 3)}$ & $\mathrm{S}=11187.54 \mathrm{~N}^{-0.333}$ \\
Cross-fillet-welded joint & $\mathrm{S}=6294.15 \mathrm{~N}^{(-1 / 3)}$ & $\mathrm{S}=8954.64 \mathrm{~N}^{(-1 / 3)}$ & $\mathrm{S}=6917.13 \mathrm{~N}^{-0.333}$ \\
\hline
\end{tabular}

\section{Test Results}

\subsection{Tensile mechanical properties}

The control axial force $\mathrm{kF}_{\mathrm{y}}$ of the fatigue test was determined according to GB/T3075-2008. Therefore, tensile mechanical performance test was carried out on the welded joint specimens to determine $F_{y}$. The load-displacement relationship curves obtained from the tensile tests of the three types of weld connections are shown in Figure 2, and the test results of each specimen are presented in Table 7.

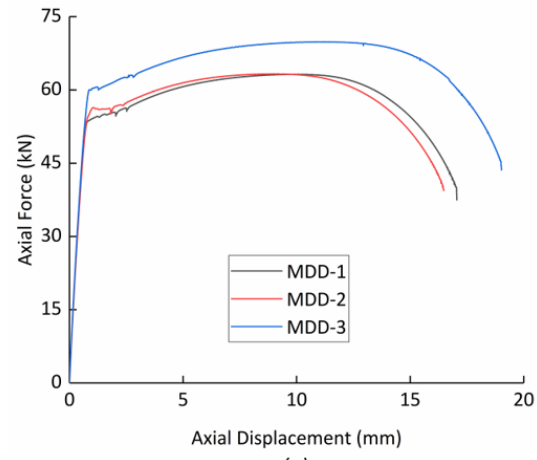

(a)

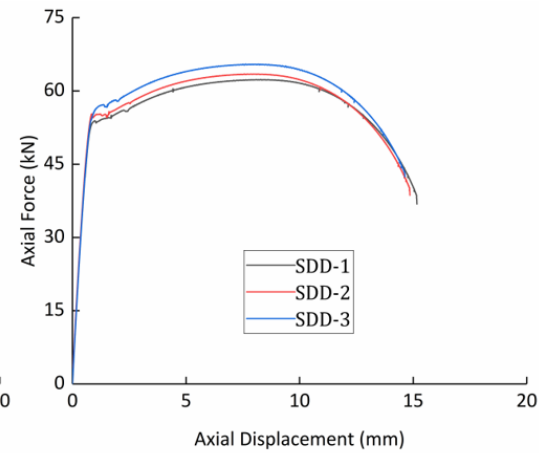

(b)

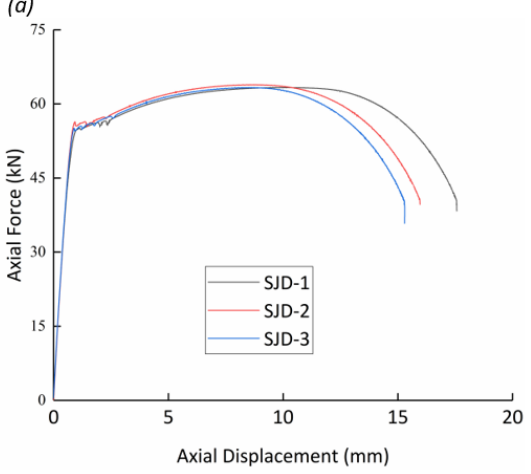

(c)

Fig. 2 Monotonic tensile load displacement curve: (a) Butt-welded joint, (b) Cross-butt-welded joint, (c) Cross-fillet-welded joint.

Tab. 7 Tensile test results

\begin{tabular}{|c|c|c|c|c|c|c|}
\hline Connection type & Specimen number & $F_{y} / k N$ & $\mathrm{~F}_{\mathrm{u}} / \mathrm{kN}$ & $\mathrm{f}_{\mathrm{y}} / \mathrm{MPa}$ & $\mathrm{f}_{\mathrm{u}} / \mathrm{MPa}$ & $F_{y} / F_{u}$ \\
\hline \multirow[t]{4}{*}{ Butt-welded joint } & MDD-1 & 54.5 & 63.2 & 454.2 & 526.7 & 0.86 \\
\hline & MDD-2 & 57.5 & 63.1 & 479.2 & 525.8 & 0.91 \\
\hline & MDD-3 & 60.5 & 69.7 & 504.2 & 580.8 & 0.87 \\
\hline & average & 57.5 & 65.3 & 479.2 & 544.2 & 0.88 \\
\hline \multirow{4}{*}{$\begin{array}{c}\text { Cross-butt-welded } \\
\text { joint }\end{array}$} & SDD-1 & 54.0 & 62.3 & 450.0 & 519.2 & 0.87 \\
\hline & SDD-2 & 55.2 & 63.4 & 460.0 & 528.3 & 0.87 \\
\hline & SDD-3 & 58.0 & 65.4 & 483.3 & 545.0 & 0.89 \\
\hline & average & 55.7 & 63.7 & 464.2 & 530.8 & 0.87 \\
\hline \multirow{4}{*}{$\begin{array}{l}\text { Cross-fillet-welded } \\
\text { joint }\end{array}$} & SJD-1 & 55.0 & 63.3 & 458.3 & 527.5 & 0.87 \\
\hline & SJD-2 & 56.3 & 63.6 & 469.2 & 530.0 & 0.89 \\
\hline & SJD-3 & 55.2 & 63.9 & 460.0 & 532.5 & 0.86 \\
\hline & average & 55.5 & 63.6 & 462.5 & 530.0 & 0.87 \\
\hline
\end{tabular}


The primary tensile failure positions of the three types of weld connection specimens are all near the arc transition section of the specimens, basically the same as the failure position of the base metal specimen under the same conditions, and there is no tensile failure of the welds. These indicate that the weld joints meet the design requirements of equal strength. The tensile fractures of all specimens show typical plastic deformation characteristics. The differences of fracture yield and ultimate load among three kinds of joint specimens are less than $5 \%$, and the yield strength ratio is about 0.87 . These imply that the welding quality of the specimens meets the requirements, and the tensile failure strength mainly depends on the properties of the base material. The load-displacement relationship curve of the specimen can be divided into the elastic stage, the yield stage, the strengthening stage and the failure stage, consistent with the tensile failure of the low-alloy high-strength steel base material.

\subsection{Fatigue test results}

The axial force of fatigue loading of welded joint specimens is based on the average yield load obtained from tensile test in Table 7. The average yield load of all kinds of welded joints is $57.5 \mathrm{kN}$, and the fatigue performance tests under different loading factors $\mathrm{K}$ are taken into account. The results are shown in Table 8, 9 and 10. The fatigue failure positions of the three types of specimens are all at the weld connection. It shows that the fatigue failure of welded joint specimens caused by the inhomogeneity, geometric discontinuity, and residual stress of the weld or by the unavoidable defects during in the welding all appear at the welding seam.

Tab. 8 Fatigue test parameters and results of butt-welded joint

\begin{tabular}{cccccc}
\hline Specimen number & $\mathbf{K}$ & $\mathbf{S}_{\max } / \mathrm{MPa}$ & $\mathbf{F} / \mathbf{H z}$ & $\mathbf{S} / \mathbf{M P a}$ & $\mathbf{N} / \mathbf{c y c l e}$ \\
\hline MDX-1 & 0.62 & 297.08 & 10 & 267.38 & 1625182 \\
MDX-2 & 0.70 & 335.42 & 10 & 301.88 & 157084 \\
MDX-3 & 0.68 & 325.92 & 10 & 293.33 & 380915 \\
MDX-4 & 0.60 & 287.50 & 10 & 258.75 & 1432011 \\
MDX-5 & 0.65 & 311.46 & 10 & 280.31 & 458116 \\
MDX-6 & 0.58 & 277.92 & 10 & 250.13 & 1828264 \\
MDX-7 & 0.62 & 297.08 & 10 & 267.38 & 703875 \\
MDX-8 & 0.60 & 287.50 & 10 & 258.75 & 1669477 \\
MDX-9 & 0.55 & 263.54 & 10 & 237.19 & 1953255 \\
MDX-10 & 0.70 & 335.42 & 10 & 301.88 & 284.63 \\
MDX-11 & 0.66 & 316.25 & 10 & 271.69 & 382975 \\
MDX-12 & 0.63 & 301.88 & 10 & 945216 \\
\hline
\end{tabular}

Tab. 9 Fatigue test parameters and results of cross-butt-welded joint

\begin{tabular}{cccccc}
\hline Specimen number & $\mathbf{K}$ & $\mathbf{S}_{\mathbf{m a}} \mathbf{X} / \mathbf{M P a}$ & $\mathbf{F} / \mathbf{H z}$ & $\mathbf{S} / \mathbf{M P a}$ & $\mathbf{N} / \mathbf{C y c l e}$ \\
\hline SDX-1 & 0.70 & 335.42 & 10 & 301.88 & 26561 \\
SDX-2 & 0.60 & 287.50 & 10 & 258.75 & 58686 \\
SDX-3 & 0.55 & 263.54 & 10 & 237.19 & 38878 \\
SDX-4 & 0.45 & 215.63 & 10 & 194.06 & 120228 \\
SDX-5 & 0.40 & 191.67 & 10 & 172.50 & 241913 \\
SDX-6 & 0.30 & 143.75 & 10 & 129.38 & 662669 \\
SDX-7 & 0.28 & 134.17 & 10 & 120.75 & 456426 \\
SDX-8 & 0.25 & 119.79 & 10 & 107.81 & 1052318 \\
SDX-9 & 0.22 & 105.42 & 10 & 94.88 & 2000000 \\
SDX-10 & 0.24 & 115.00 & 10 & 103.50 & 2000000 \\
SDX-11 & 0.27 & 129.38 & 10 & 116.44 & 1075740 \\
SDX-12 & 0.23 & 95.83 & 10 & 86.25 & 980012 \\
\hline
\end{tabular}


Tab. 10 Fatigue test parameters and results of cross-fillet-welded joint

\begin{tabular}{cccccc}
\hline Specimen number & $\mathbf{K}$ & $\mathrm{S}_{\max } / \mathbf{M P a}$ & $\mathbf{F} / \mathbf{H z}$ & $\mathrm{S} / \mathrm{MPa}$ & $\mathbf{N} / \mathbf{C y c l e}$ \\
\hline SJX-1 & 0.25 & 119.79 & 10 & 107.81 & 515925 \\
SJX-2 & 0.22 & 105.42 & 10 & 94.88 & 379449 \\
SJX-3 & 0.20 & 95.83 & 10 & 86.25 & 2000000 \\
SJX-4 & 0.28 & 134.17 & 10 & 120.75 & 186346 \\
SJX-5 & 0.19 & 91.04 & 10 & 81.94 & 2000000 \\
SJX-6 & 0.21 & 100.63 & 10 & 90.56 & 1734188 \\
SJX-7 & 0.24 & 115 & 10 & 103.50 & 1094757 \\
SJX-8 & 0.26 & 124.58 & 10 & 112.13 & 914886 \\
SJX-9 & 0.27 & 129.38 & 10 & 116.44 & 1184697 \\
SJX-10 & 0.30 & 143.75 & 10 & 129.38 & 277720 \\
SJX-11 & 0.29 & 138.96 & 10 & 125.06 & 322692 \\
SJX-12 & 0.23 & 110.21 & 10 & 99.19 & 480348 \\
\hline
\end{tabular}

After analyzing the test data, it is found that the results of data points MDX-7, SDX-7, SDX-12, SJX-2 and SJX-4 deviate significantly from the overall result, so they will be discarded as abnormal data in the analysis. The logarithmic linear relationship between the stress range $S$ and the number of cycles $\mathrm{N}$ is obtained by fitting of the test data with reference to Eq. (4a). The P-S-N relationships of 0.95 survival rate can also be obtained. The fitting S-N curves in logarithmic coordinates are shown in Figure 3 The S-N relationships of the three types of welds are listed in Table 11.

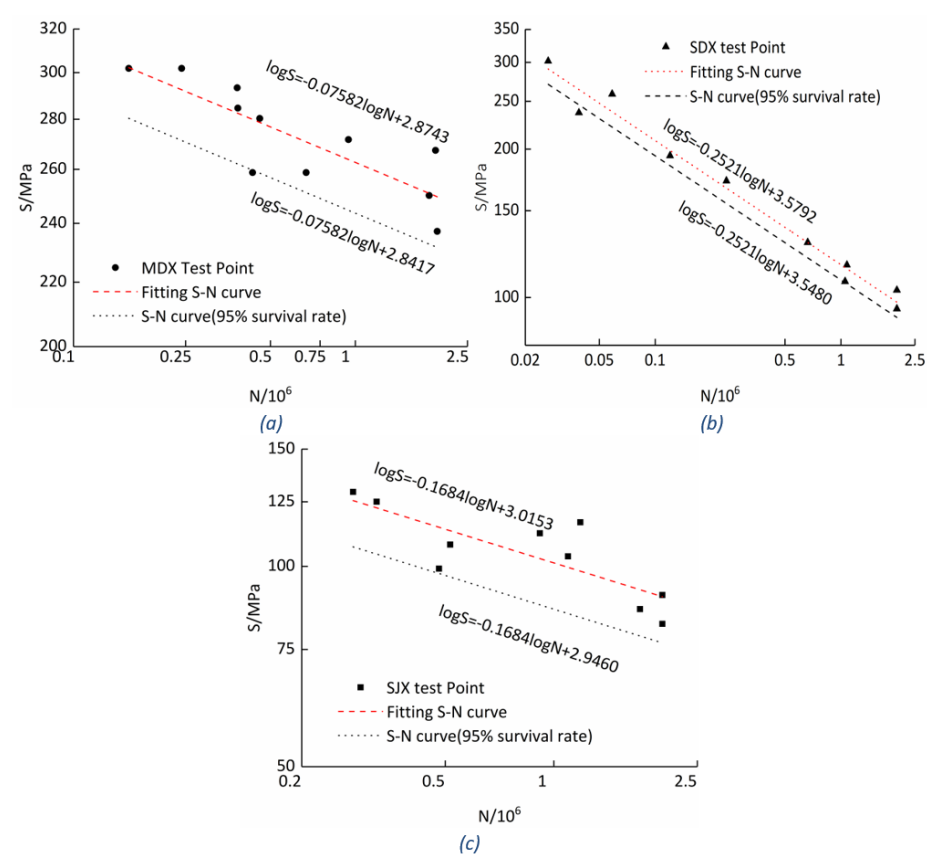

Fig. 3 Fitting S-N curve in logarithmic coordinates: (a) Butt-welded joint, (b) Cross-butt-welded joint, (c) Cross-fillet-welded joint.

Tab. 11 Fitting S-N equation

\begin{tabular}{cccccc}
\hline \multirow{2}{*}{ Type } & \multicolumn{2}{c}{ General form } & & \multicolumn{2}{c}{ Logarithmic form } \\
\cline { 2 - 3 } \cline { 5 - 6 } & S-N equation & 95\% S-N equation & & S-N equation & 95\% S-N equation \\
\hline MDX series & $S=748.69 N-0.07582$ & $S=694.541 \mathrm{~N}-0.07582$ & & $\log S=2.8743-0.07582 \log N$ & $\log S=2.8417-0.07582 \operatorname{logN}$ \\
SDX series & $S=3794.90 N-0.2521$ & $S=3531.83 N-0.2521$ & & $\log S=3.792-0.2521 \operatorname{logN}$ & $\operatorname{logS}=3.5480-0.2521 \log N$ \\
SJX series & $S=1035.86 N-0.1684$ & $S=883.08 N-0.1684$ & & $\log S=3.0153-0.1684 \operatorname{logN}$ & $\log S=2.9460-0.1684 \log N$ \\
\hline
\end{tabular}


The fitting results of test data are compared with the S-N curves of corresponding connection fatigue life stipulated by various standards, as shown in Figure 4. The ultimate fatigue strength of the three connections under the action of 2 million stress cycles is compared with the standard value, as shown in Table 12.

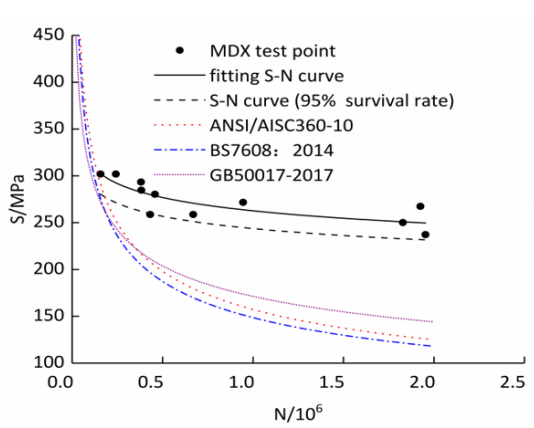

(a)

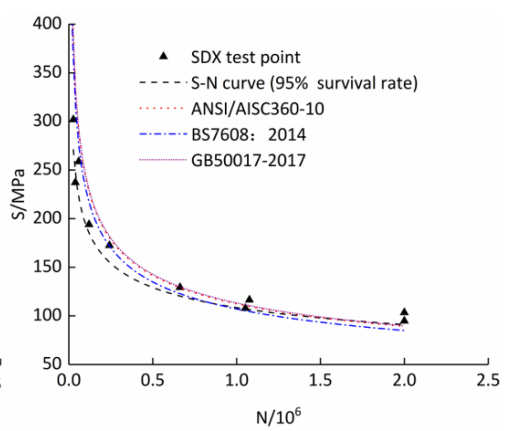

(b)

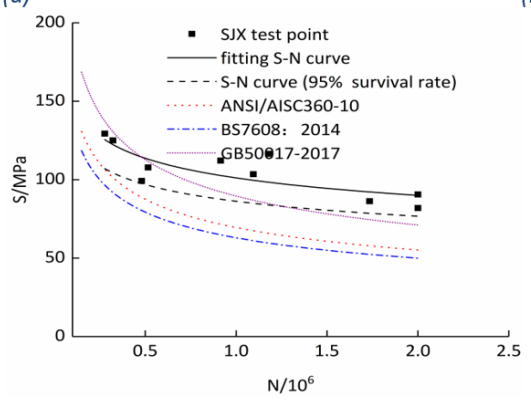

(c)

Fig. 4 Contrast S-N curves in Cartesian coordinates: (a) Butt-welded joint, (b) Cross-butt-welded joint, (c) Cross-fillet-welded joint.

Tab. 12 Comparison of fatigue limit strength

\begin{tabular}{cccccc}
\hline \multirow{2}{*}{ Connection type } & \multicolumn{5}{c}{ S /MPa } \\
\cline { 2 - 6 } & Fitted value & 95\% survival & BS7608: 2014 & GB50017-2017 & ANSI/AISC360-10 \\
\hline Butt-welded joint & 249.2 & 231.2 & 117.9 & 144.1 & 124.8 \\
Cross-butt-welded joint & 97.9 & 91.1 & 85 & 90 & 89.2 \\
Cross-fillet-welded joint & 90 & 76.7 & 50 & 71.1 & 55.2 \\
\hline
\end{tabular}

From the fitting and calculation results of the test data, it can be known:

1. The values of MDX sample fitting curve and $95 \%$ survival rate curve are much larger than the values corresponding to BS7608: 2014, GB50017-2017 and ANSI/AISC360-10 standard curves. Among them, the fatigue limit of the 95\% survival rate corresponding to $2 \times 10^{6}$ stress cycles is 1.96 times the calculated value of BS7608: 2014, 1.6 times the calculated value of GB50017-2017, and 1.85 times the calculated value of ANSI/AISC360-10. The calculated values of the standard curves also deviate significantly. After the number of stress cycles exceeds 180,000 times, the calculated value of GB50017-2017 is greater than that of BS7608:2014, and after it exceeds 360,000, the calculated value of GB50017-2017 is greater than that of ANSI/AISC360-10. On the whole, BS7608:2014 calculated value is the most conservative, while GB50017-2017 calculated value is closer to the fitting curve.

2. The SDX sample fitting curve and $95 \%$ survival rate curve are close to the standard curves, and the difference among the standard curves is quite small. Before the number of stress cycles reaches 0.86 million, 1.7 million and 1.54 million, the $95 \%$ survival rate curve is higher than BS7608:2014, GB50017-2017 and ANSI/AISC360-10 curves. At $2 \times 10^{6}$ stress cycles, the fatigue limit of $95 \%$ survival rate is respectively $8.1 \%, 2.1 \%$, and $3.0 \%$ higher than the calculated values of BS7608:2014, GB50017-2017 and ANSI/AISC360-10.

3. The SJX sample fitting curve and 95\% survival rate curve are closer to GB50017-2017 curve; BS7608:2014 and ANSI/AISC360-10 curves are more conservative. After the number of stress cycles exceeds 1.26 million, the $95 \%$ survival rate curve is higher than the GB50017-2017 curve. The fatigue limit of 95\% survival rate corresponding to $2 \times 10^{6}$ stress cycles is 53.4\%, 7.9\%, and 38.9\% higher than the calculated values of BS7608: 2014, GB50017-2017 and ANSI/AISC360-10, respectively. 


\subsection{Fracture analysis}

The fracture positions of all kinds of specimens under fatigue test are at the weld joint. MDX- 6 specimen was damaged after 1828264 stress cycles under load of $250.1 \mathrm{MPa}$; SDX-7 specimen was damaged under the load of $116.4 \mathrm{MPa}$ after 456426 stress cycles; SJX-1 specimen broke down under the load of $107.8 \mathrm{MPa}$ after 515925 stress cycles. The typical macroscopic fractures of the specimen are shown in Figure 5. All the fractures have typical characteristics of fatigue fracture, and they are grouped into crack initiation zone I, crack propagation zone II and final fast fracture zone III. The cracks of welded joint are generally initiated in the heat-affected zone or near the fusion zone. The fracture surface of the specimen before instant fatigue failure is flat and smooth. The instantaneous fracture zone is rough, consistent with the obvious characteristic appearance of the coarse particles in plastic deformation.

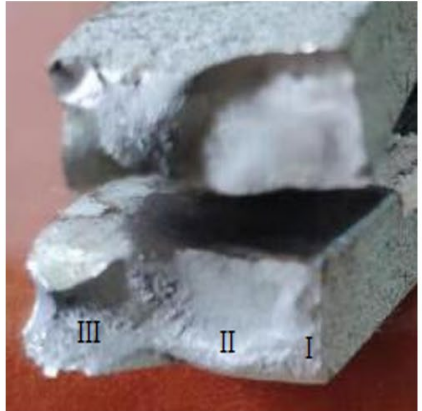

(a)

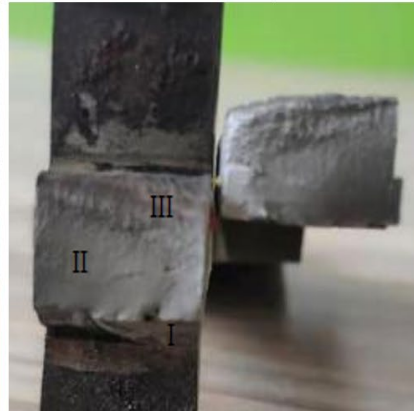

(b)

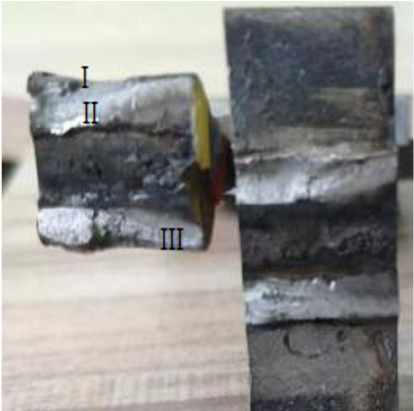

(c)

Fig. 5 Fatigue Fracture of Specimens: (a) Butt-welded joint (MDX-6), (b) Cross-butt-welded joint (SDX-7), (c) Cross-fillet-welded joint (SJX-1).

A Hitachi S-4800 scanning electron microscope was used to scan the microscopic morphology of the fractures of the above three specimens. The results are shown in Figures 6,7 and 8 . The fractures of the specimens were magnified by 50 times, 500 times and 1000 times to observe the three boundary areas of the fracture. Images in (a) show the crack initiation: the inherent defects of fatigue crack can be found under 50 times of magnification. Images in (b) show the crack propagation: the fatigue streaks caused by cyclic loading and the secondary cracks caused by asynchronous crack propagation are observed under 500 times of magnification. Images in (c) show the final fast fracture: after 1000 times of magnification, dimples of varying sizes can be observed, showing the rapid expansion of material damage.

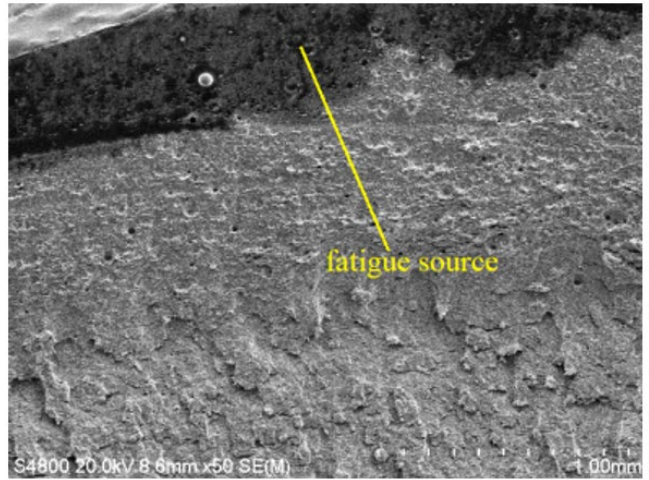

(a)

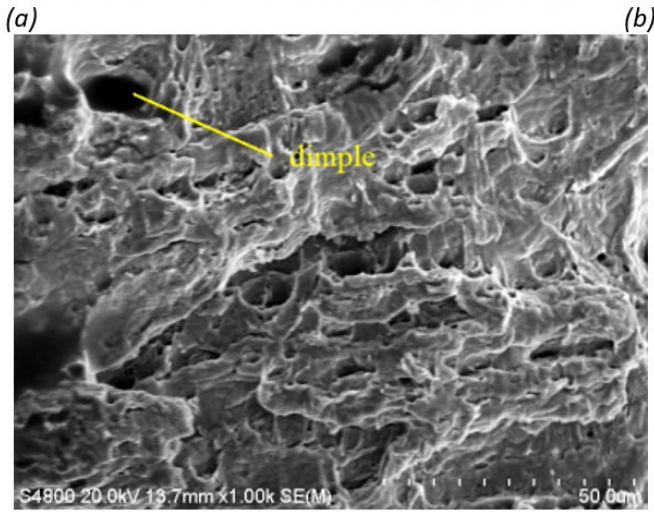

(c)

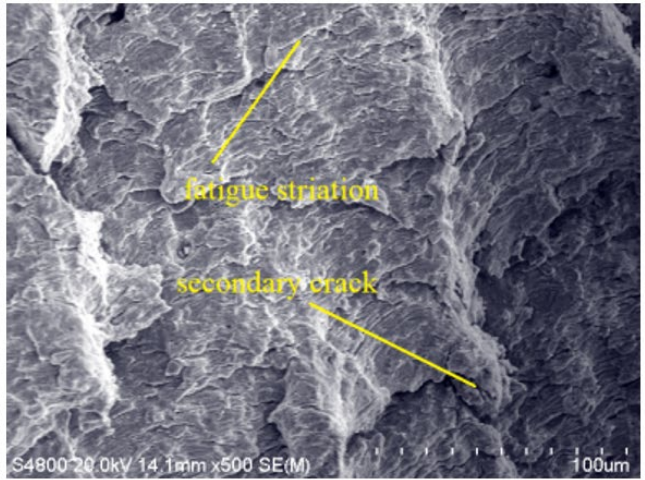

(b)

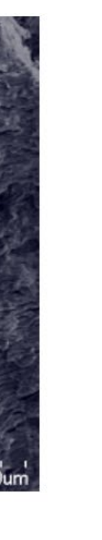




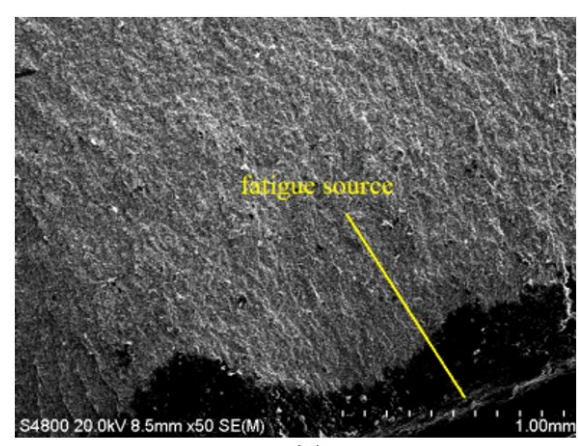

(a)

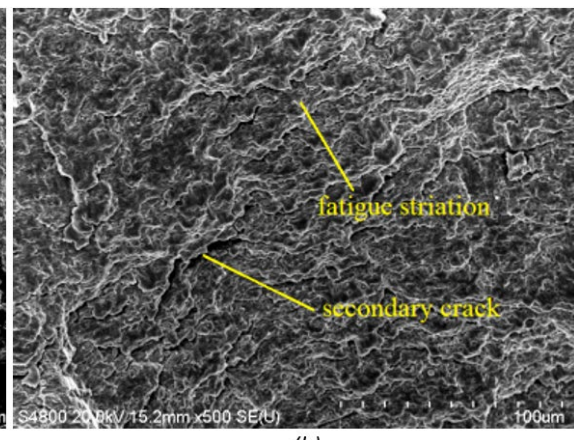

(b)

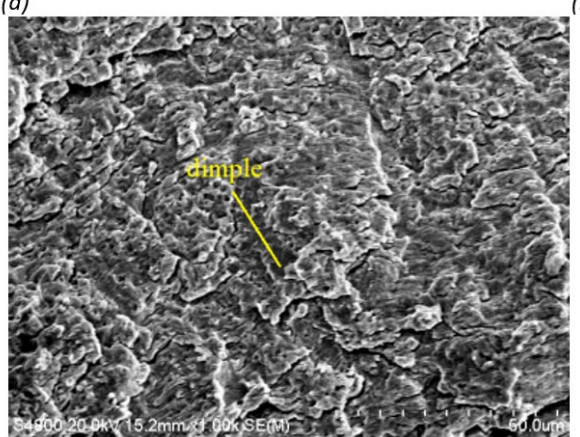

(c)

Fig. 7 Fracture morphology of cross-butt-welded joint (SDX-7): (a) The crack initiation, (b) The crack propagation, (c) The final fast fracture.
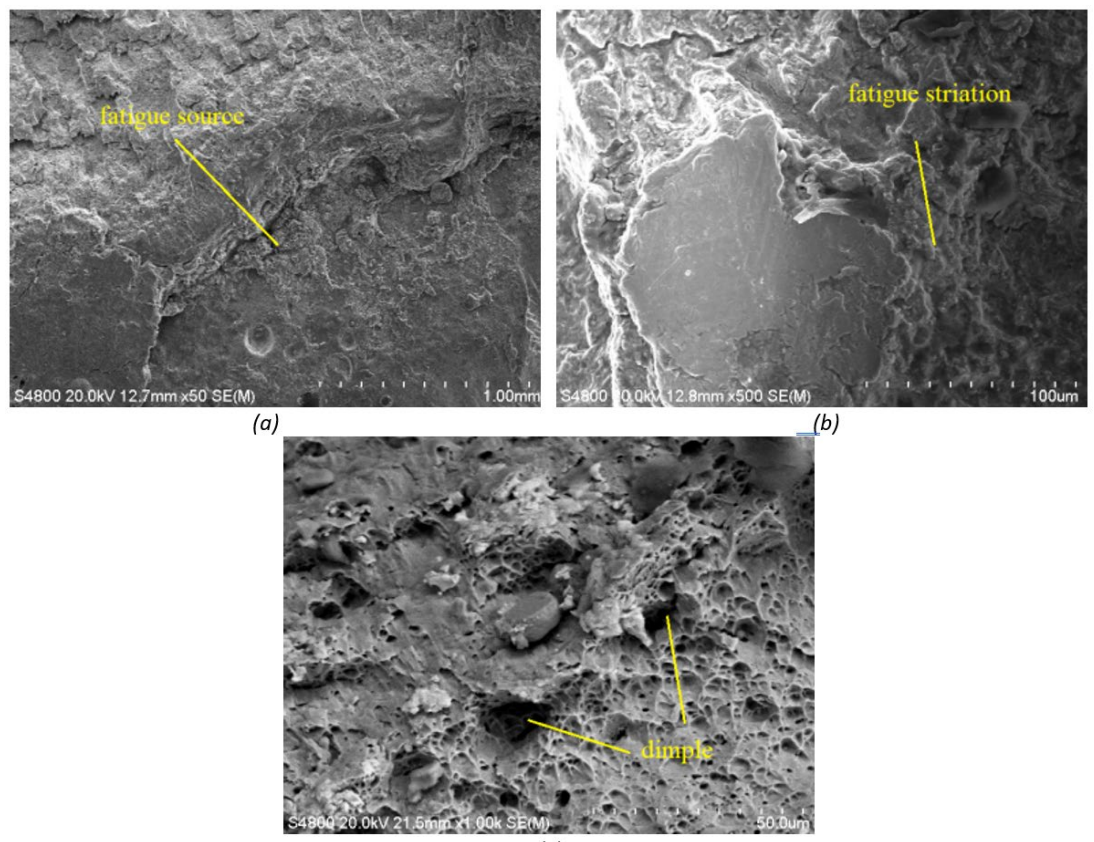

(c)

Fig. 8 Fracture morphology of cross-fillet-welded joint (SJX-1): (a) The crack initiation, (b) The crack propagation, (c) The final fast fracture.

\subsection{Fatigue displacement analysis}

The fatigue test was set to stop when the specimen breaks down or when the number of stress cycles reaches 2 million. Due to the small cyclic stress, the displacement of unbroken specimens during fatigue loading was small and the maximum value basically remained unchanged. The fatigue displacement of fractured specimens varying with the ratio of $\mathrm{N}$ to $\mathrm{N}_{\mathrm{f}}$ is shown in Figure 9. In this figure, $\delta$ is the displacement of the specimen under load, $\mathrm{N}$ is the number of loading cycles, and $\mathrm{N}_{\mathrm{f}}$ is the fatigue life of specimen. As shown in Figure 9 , the displacement change processes of the four typical specimens correspond to the two stages of crack propagation zone II and instantaneous fracture zone III. The crack initiation zone I, the crack initiation stage, is directly skipped. This is consistent with the fatigue factures of the specimens. 


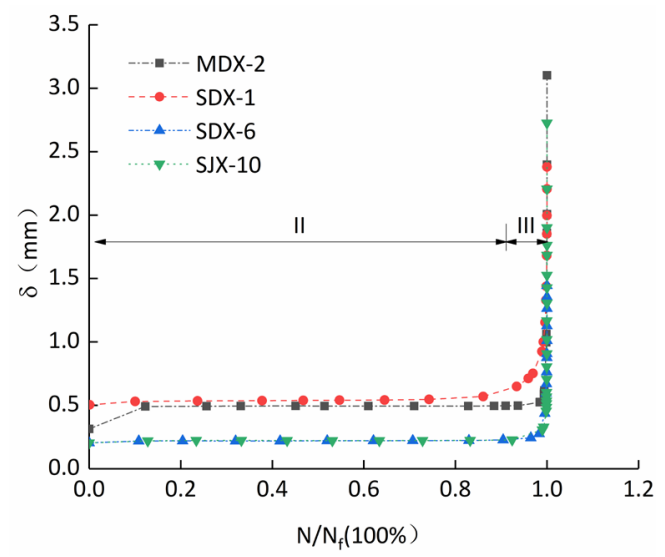

Fig. 9 Fatigue displacement curve.

When the ratio of $\mathrm{N} / \mathrm{N}_{\mathrm{f}}$ is below $0.9, \mathrm{MDX}-2$ and SDX-1 specimens have the maximum fatigue displacement of $0.5 \mathrm{~mm}$ under the action of $301.88 \mathrm{MPa}$ ultimate stress; SDX-6 and SJX-10 specimens have the maximum fatigue displacement of $0.2 \mathrm{~mm}$ under the action of $129.38 \mathrm{MPa}$ ultimate stress. The displacement of all specimens under load is basically proportional to the applied load, and the extreme displacement in the crack propagation zone remains unchanged. When the ratio of $\mathrm{N} / \mathrm{N}_{\mathrm{f}}$ is larger than 0.9, the specimen enters the instantaneous fracture zone, and the remaining uncracked part shows obvious plastic deformation, and the displacement starts to increase rapidly until the specimen fractures.

\section{Fatigue Damage Analysis}

Fatigue failure can be seen as the phenomenon of gradual damage or even fracture of materials or connections under cyclic loading. The fatigue damage theory can estimate the remaining service life based on the service conditions of the engineering structure. Under a given cyclic load, the damage variable remains constant during a stress cycle. In high-cycle fatigue, the number of cycles $N$, the damage variable $D$ and the fatigue life $N_{f}$ satisfy Eq. (10). And the fatigue life $\mathrm{N}_{\mathrm{f}}$ can be calculated by Eq. (11) under uniaxial tension fatigue conditions (Lou, 1991).

$D=1-\left(1-\frac{N}{N_{f}}\right)^{1 /(\beta+2)}$

$N_{f}=\frac{(\beta+1)\left(s_{\max }^{\beta+1}-s_{\min }^{\beta+1}\right)^{-1}}{2 B(\beta+2)}$

where $S_{\max }$ and $S_{\min }$ are the maximum and minimum stresses under cyclic loading, and $B$ and $\beta$ are material constants, which can be determined by fatigue tests.

According to the fatigue test in Table 11, the $\beta$ values of MDX, SDX and SJX specimens can be obtained by fitting the S-N power function relationship, which are $12.1891,2.9667$, and 4.9382, respectively. The fatigue damage curves are obtained by substituting the $\beta$ value into Eq. (10), as shown in Figure 10.

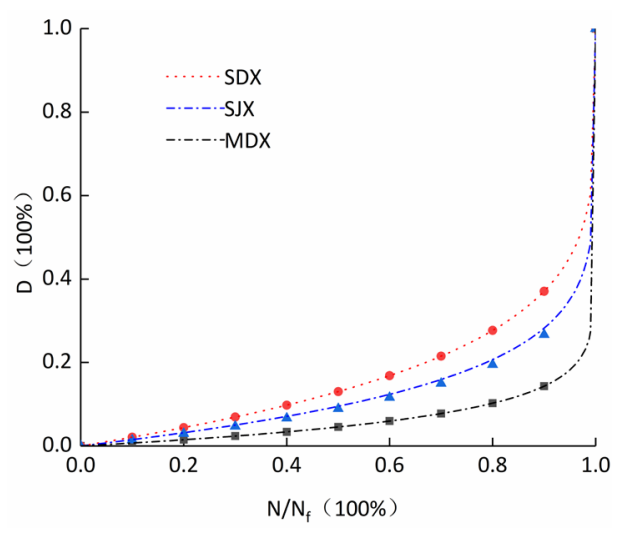

Fig. 10 Fatigue damage curve. 
It can be seen from Figure 10 that when $\mathrm{N} / \mathrm{N}_{\mathrm{f}}<0.5$, the damage variable $\mathrm{D}$ increases slowly as the cycle ratio approaches a linear relationship, and crack bands with roughly constant spacing can be observed in the crack propagation zone. When $0.5<\mathrm{N} / \mathrm{N}_{\mathrm{f}}<0.9$, the damage variable $\mathrm{D}$ increases rapidly and non-linearly with the $\mathrm{N} / \mathrm{N}_{\mathrm{f}}$ ratio, and the crack band spacing in the crack propagation zone gradually increases. When $N / N_{f}>0.9$, the damage variable $D$ approaches 1 with the increasing $\mathrm{N} / \mathrm{N}_{\mathrm{f}}$ ratio, and the specimens enter the instantaneous fracture stage. Before the specimens fracture, the cumulative damage index of MDX specimen is about $25 \%$, followed by SJX specimen (50\%) and SDX specimen (60\%). It is therefore can be concluded that the damage development rate of MDX is the slowest, followed by SJX and SDX successively. The reason may be that the stress concentration at the weld joints is different. The removal of the excess height after welding the MDX specimen reduces the effect of stress concentration.

\section{Comparative Analysis of Joint Fatigue}

Extensive studies have been carried out on the fatigue test of welded joints, and most of them focus on butt-welded joints and cross-butt-welded joints. However, there are few comparative analyses of the fatigue test results. It is difficult to compare the fatigue tests due to the large number of loading parameters, different stress calculation methods, and inconsistent fitting variables. The loading parameters involved in fatigue test usually include the maximum stress, stress ratio, stress range, stress amplitude, load waveform and loading frequency. As for the calculation of the cross-sectional stress of specimen, most tests use the nominal cross-sectional area, and some tests use the actual cross-sectional area. In addition, the stress $\mathrm{S}$ of $\mathrm{S}-\mathrm{N}$ curve fitting is often confused. In some tests, the maximum stress $\mathrm{S}_{\text {max }}$ is adopted, while the stress range or stress amplitude is used in some other.

In this paper, the S-N curves of some references are compared while retaining their original experimental data (Guo et al., 2018a; Guo et al., 2018b; Guo et al., 2018c; Shi et al., 2014a; Shi et al., 2014b; Zong et al.,2017a). In the S-N curve, $S$ represents the stress range, and the stress ratio in the cited literature is all 0.1 . The steel types, plate thicknesses and fitting curves of test points are shown in Figure 11. It can be known from Figure 11 that the test data of various welded joints are quite disperse, and that most of the test points are distributed above the standard curve. It indicates that the fatigue design of typical welds according to the standard curve can meet engineering requirements. The fatigue properties of similar welded steel joints with varying strength grades are close, implying that the strength grade of steel has little impact on the fatigue performance of joints. The test value of cross-fillet-welded joint with a plate thickness of $12 \mathrm{~mm}$ is obviously lower than that with a plate thickness of $8 \mathrm{~mm}$, indicating that the fatigue performance of connection becomes worse with the increasing plate thickness. There are few studies on the fatigue performance of other types of welded joints, like butt-welded joints, in the standards. Thus, more fatigue tests or theoretical studies on other connections should be carried out to improve the standards.

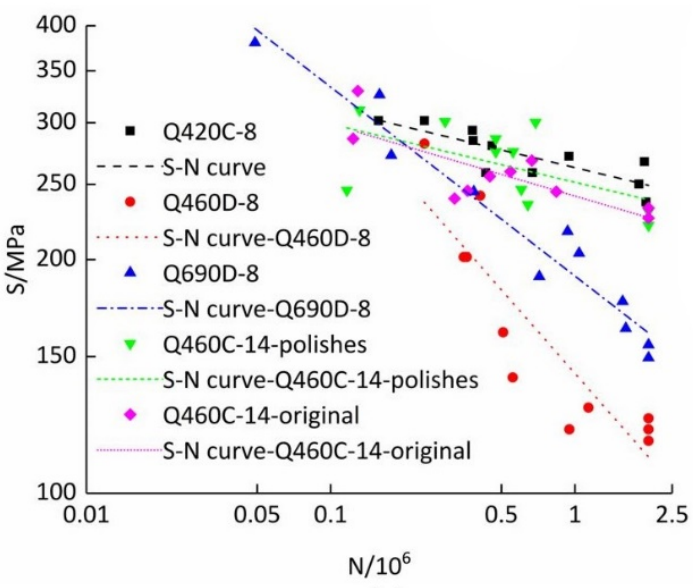

(a)

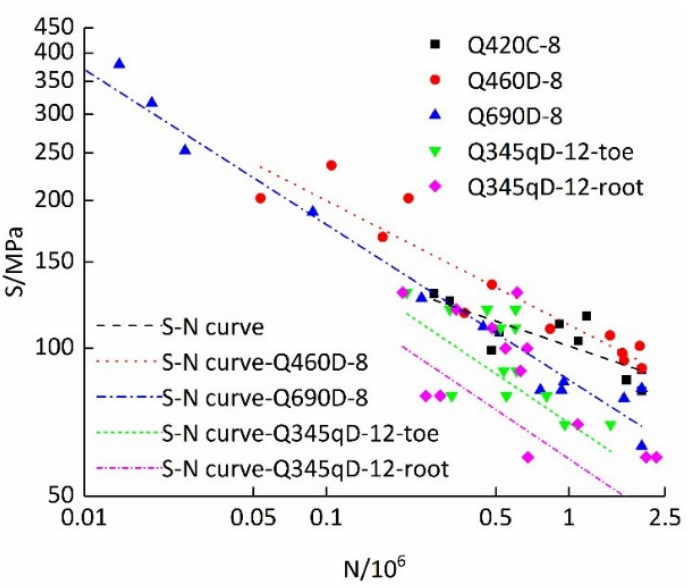

(b)

Fig. 11 Contrast S-N curves in Cartesian coordinates: (a) Butt-welded joint, (b) Cross-fillet-welded joint.

\section{Conclusions}

The following conclusions are drawn from the experimental study on the fatigue properties of three typical welded joints of $8 \mathrm{~mm}$ thick Q420C steel plate: butt-welded joints, cross-butt-welded joints, and cross-fillet-welded joints. 
1. The specimens all showed typical fatigue failure characteristics. The fracture was mainly distributed across the crack propagation zone and the instantaneous fracture zone. There were clear fatigue crack bands in the crack propagation zone, and the fracture of the instantaneous fracture zone was consistent with the plastic tensile fracture.

2. The values of fitting curve of butt-welded joint and the $95 \%$ survival rate curve are much larger than those of BS7608: 2014, GB50017-2017 and ANSI/AISC360-10 standard curves, indicating a large safety margin. It is therefore suggested to moderately increase the standard value.

3. The fitting curve of cross-butt-welded joint agreed well with the standard curves, and the difference among the three standard curves was quite small, indicating a small safety margin of the standards. It is necessary to increase the fatigue test research of cross-butt-welded joint and have similar safety reserve with other weld joints.

4. The fitting curve of cross-fillet-welded joint and 95\% survival rate curve were closer to GB50017-2017 curve. When the number of stress cycles was below 1.26 million, the test values were smaller than the calculated value of $95 \%$ survival rate, and BS7608: 2014 and ANSI/AISC360-10 curves were more conservative.

5. The comparison between cross-fillet-welded joints of $12 \mathrm{~mm}$ and $8 \mathrm{~mm}$ steel plates showed that the fatigue performance of joints became worse with the increasing thickness of plate. In the future research, finite element numerical simulation can be used to quantify the impact of steel plate thickness on joint fatigue performance. At the same time, the experimental and theoretical research on the fatigue performance of other joints can be conducted.

\section{Acknowledgements}

This work was funded by the Scientific Research Project of Universities in Inner Mongolia (No. NJZY21326).

Author's Contribuitions: Conceptualization, Yongming Xing ; Investigation,Liguo Yang ; Writing - original draft,Liguo Yang; Writing - review \& editing, Yongming Xing and Liguo Yang; Funding acquisition, Yongming Xing ; Resources, Liguo Yang.

Editor: Marcílio Alves

\section{References}

ANSI/AISC360-10 (2010) Specification for Structural Steel Buildings. ANSI/AISC360-10,American Institute of Steel Construction, Chicago IL, USA.

BS7608-2014 (2015) Guide to fatigue design and assessment of steel products: BS7608-2014, British standards Institution, London, UK.

Chen SF (2005) Principle of steel structure design,3rd edition, Science Press, Beijing, CHN (in Chinese).

Cheng F, Hu CS, Wang JS, Guo N, Wu HY, Li ZR, Zhang DC (2017) Experimental research on fatigue behavior of Q420 high strength steel, Steel Construction 32(11):12-15(in Chinese).

Custafsson M (2002) Thickness effect in fatigue of welded extra high strength steel joints, Proceedings of the Eighth International Fatigue Congress, Stockholm, Sweden, 205-224.

GB50017-2017 (2017) Code for design of steel Structures GB50017-2017, Planning Press, Beijing, CHN (in Chinese).

GB50611-2011 (2012) Code for welding of steel structures, China Construction Industry Press, Beijing, CHN (in Chinese).

GB/T1591-2008 (2009)High strength Low alloy structural steels, China Standard Press, Beijing, CHN (in Chinese).

GB/T3075-2008 (2008) Metallic materials-Fatigue testing-Axial force controlled method, China Standard Press, Beijing, CHN (in Chinese).

Guo HC, Hao LP, Li YL, Liu YH, Wan JH (2018a) Experimental study on fatigue Performance of Q460D high-strength steel and its welded joints, Journal of Building Structures 39(8):157-164(in Chinese). 
Guo HC, Wan JH, Liu YH, Hao JP (2018b) Experimental study on fatigue performance of high strength steel welded joints, Thin Walled Structures 131:45-54.

Guo HC, Wan JH, Liu YH,Wang DF (2018c) Experimental study on fatigue Performance of Q690D high strength steel welded joints, China Civil Engineering Journal 51(9):1-9(in Chinese).

Janosch JJ, Koneczny H, Debiez S, Statnikov, EC, Troufiakov VJ, Mikhee PP (1996) Improvement of fatigue strength in welded joints (in HSS and in aluminium alloys) by ultrasonic hammer peening Welding in the World 37 (1)72-83.

JG/T 288-2013 (2013) Test methods for cruciform joints of building steel structures, China Standard Press, Beijing, CHN (in Chinese).

Jia DF, Wang YQ, Cui J, Liao XW, Gu HY (2017) Experimental research on fatigue performance and fracture mechanism of Q345qD butt welds. Industrial Construction 47(11)175-180 (in Chinese).

Lei HG, Fu Q, Liu XJ (2010) Research progress of steel structure fatigue in past 30 years in China. Journal of Building Structures (Supplementary Issue 1) 31(SI)84-91 (in Chinese).

Leitner M,Stoschka M, Schorghuber M, Eichlseder W (2011) Fatigue behavior of high-strength steels using an optimized welding process and high frequency peening technology, IIW International Conference, International Institute of Welding, Chennai, India,17-22.

Lou ZW (1991) Damage mechanics foundation, Xi'an Jiaotong University Press, Xi'an Shaanxi Province, CHN (in Chinese).

Okawa T, Shimanuki H, Funatsu Y, Nose T, Sumi Y (2013)Effect of preload and stress ratio on fatigue strength of welded joints improved by ultrasonic impact treatment, Welding in the World 57:235-241.

Shi G, Zhang JX (2014a) Fatigue Performance test study on high strength steel Q460C and its welded connection, Building Structure 44(17):1-6 (in Chinese).

Shi G, Zhang JX (2014b) Fatigue test of high strength steel Q460D, Industrial Construction 44(3):6-10(in Chinese).

Weich I (2008) Fatigue behavior of mecnical post welds treated weld depending on the edge layer condition PHD Thesis, Technischen Universitat Carolo-Wilhelmina, Braunschweig.

Zhang YF, Chen Z, Liu GH (2020) Study on fatigue property of Q420 steel with different welding process, Welding Technology 49(6):13-17(in Chinese).

Zong L, Shi G, Wang YQ, Yan JB, Ding Y (2017a)Investigation on fatigue behavior of load-carrying fillet welded joints based on mix-mode crack propagation analysis. Archives of Civil and Mechanical Engineering 17:677-686,

Zong L, Shi G, Wang YQ, Li ZX, Ding Y (2017b) Experimental and numerical investigation on fatigue performance of non-loadcarrying fillet welded joints, Journal of Constructional Steel Research 130:193-201. 